\title{
Renal Cortex Taurine Content Regulates Renal Adaptive Response to Altered Dietary Intake of Sulfur Amino Acids
}

\author{
Russell W. Chesney, Naomi Gusowski, and Shermine Dabbagh \\ Pediatric Renal Disease Laboratory, University of Wisconsin, Clinical Science Center, Madison, Wisconsin 53792
}

\begin{abstract}
Rats fed a reduced sulfur amino acid diet (LTD) or a high-taurine diet (HTD) demonstrate a renal adaptive response. The LTD results in hypotaurinuria and enhanced brush border membrane vesicle (BBMV) accumulation of taurine. The HTD causes hypertaurinuria and reduced BBMV uptake. This adaptation may relate to changes in plasma or renal cortex taurine concentration. Rats were fed a normal-taurine diet (NTD), LTD, or HTD for $14 \mathrm{~d}$ or they underwent: $(a) 3 \% \beta$-alanine for the last $8 \mathrm{~d}$ of each diet; (b) $3 \mathrm{~d}$ of fasting; or (c) a combination of $3 \% \beta$-alanine added for $8 \mathrm{~d}$ and $3 \mathrm{~d}$ of fasting. Each maneuver lowered the cortex taurine concentration, but did not significantly lower plasma taurine values compared with controls. Increased BBMV taurine uptake occurred after each manipulation.

Feeding 3\% glycine did not alter the plasma, renal cortex, or urinary taurine concentrations, or BBMV uptake of taurine. Feeding 3\% methionine raised plasma and urinary taurine excretion but renal tissue taurine was unchanged, as was initial BBMV uptake. Hence, nonsulfur-containing $\alpha$-amino acids did not change $\beta$-amino acid transport.

The increase in BBMV uptake correlates with the decline in renal cortex and plasma taurine content. However, since $3 \%$ methionine changed plasma taurine without altering BBMV uptake, it is more likely that the change in BBMV uptake and the adaptive response expressed at the brush border surface relate to changes in renal cortex taurine concentrations.

Finally, despite changes in urine and renal cortex taurine content, brain taurine values were unchanged, which suggests that this renal adaptive response maintains stable taurine concentrations where taurine serves as a neuromodulator.
\end{abstract}

\section{Introduction}

The renal tubular epithelium is able to conserve amino acids during periods of decreased dietary intake. In rats or mice fed a diet containing a reduced content of sulfur amino acids, the renal reabsorption and isolated tubule uptake of taurine, a sulfurcontaining $\beta$-amino acid, is enhanced (1-3). This adaptive response is expressed at the luminal surface, since isolated brush border membrane vesicles (BBMV) ${ }^{1}$ have greater uptake of tau-

Address reprint requests to Dr. Chesney, Department of Pediatrics, U C Davis Medical Center, 4301 "X" Street, Sacramento, CA 95817.

Received for publication 23 July 1984 and in revised form 1 July 1985.

1. Abbreviations used in this paper: $\alpha$-AIB, $\alpha$-aminoisobutyrate; ANOVA, analysis of variance; BBMV, brush border membrane vesicles; HTD, taurine-supplemented diet; LTD, low sulfur-amino acid diet; NTD, normal sulfur-amino acid diet.

J. Clin. Invest.

(C) The American Society for Clinical Investigation, Inc. $0021-9738 / 85 / 12 / 2213 / 09 \$ 1.00$

Volume 76, December 1985, 2213-2221 rine than BBMV from animals fed a diet containing normal amounts of sulfur amino acids (3-5). A diet high in taurine results in massive taurinuria and decreased tubule and BBMV uptake $(1,2,5)$. These changes in tubule and BBMV accumulation are associated with a change in the rate of taurine uptake $\left(V_{\max }\right)$ rather than in the affinity of the uptake system for taurine $\left(K_{\mathrm{m}}\right)$ after dietary manipulation $(1-3,5)$.

The physiological signal(s) for these adaptive changes are uncertain. Rozen et al. (3) have suggested that the prevailing plasma taurine level may govern the adaptive response, in that high plasma taurine concentrations are associated with hypertaurinuria and reduced BBMV uptake in mice and low plasma levels with hypotaurinuria and higher BBMV uptake. In addition, our group has found that in rats, plasma taurine concentrations correlate with renal cortex taurine content and that renal cortex taurine values correlate with the fractional excretion of taurine (5). What remains unclear is whether the plasma taurine level or the renal cortex taurine pool size governs this renal adaptive response. We have used the $\beta$-amino acid, $\beta$-alanine, which is transported by the same renal transport mechanism, to better understand this adaptation. $\beta$-alanine is known to reduce the taurine content of renal cortex and other tissues without greatly changing plasma levels of that amino acid (6). We have examined the nature of the adaptive response in rats fed $3 \% \beta$-alanine in their drinking water in order to gain insight into the mechanism of the renal adaptive response to altered dietary intake of amino acids. As has been shown for the renal adaptive response in dietary phosphate depletion (7), fasting will blunt the renal adaptive response to altered sulfur amino acid intake (4). We have further examined this phenomenon by determining the effect of the presence of $\beta$-alanine in the drinking water of these fasted animals.

The reason for this renal adaptive response is not clearly understood. Although whole body taurine content appears to be regulated by the kidney $(2,3,6,8,9)$, the effect of alteration in sulfur amino acid dietary intake on the taurine content of other organs suggests that the taurine content of these organs is not greatly altered $(6,10)$. To further explore this observation, the taurine concentration in various anatomic segments of the brain was measured after each diet and after $72 \mathrm{~h}$ of fasting.

\section{Methods}

Animals. Sprague-Dawley rats (King Laboratories, Oregon, IL) were used in all studies. Rats were fed one of three diets-low sulfur-amino acid diet (LTD), normal sulfur-amino acid diet (NTD), or taurine-supplemented diet (HTD)-prepared as described previously $(1,2)$. Adult rats were fed one of the three diets for $15 \mathrm{~d}$ before study at age 58-60 d (weight, 140-160 g). Previous studies have shown that the full adaptive response is evident after $6 \mathrm{~d}(2,5)$. Urine and plasma collection were made on the day of sacrifice.

Several additional groups of animals were studied: group A, rats on each of the three diets fed 3\% $\beta$-alanine (wt/vol) in their drinking water over the last $8 \mathrm{~d}$ of the 14-d dietary period; group B, rats on the NTD 
fed 3\% glycine in their drinking water for the last $8 \mathrm{~d}$; group C, rats on the NTD fed $3 \%$ methionine $(\mathrm{wt} / \mathrm{vol})$ in their drinking water for the last $8 \mathrm{~d}$. Group D rats on each of the three diets for $14 \mathrm{~d}$ were given $\beta$ alanine $(3 \% \mathrm{wt} / \mathrm{vol})$ in their drinking water on day 6 . After day 14 , all solid food was removed, and the rats were fasted, although they continued to receive $3 \% \beta$-alanine in their drinking water. Finally, group E consisted of rats fed each diet for $\mathbf{1 4} \mathrm{d}$ and then fasted for $3 \mathrm{~d}$, drinking only tap water. Rats in all groups drank the $\beta$-alanine water or the water containing glycine or methionine without demonstrating aversion.

No attempt was made to pair-feed animals, although all animals ingesting the LTD, which contained a reduced cysteine and methionine content, consistently ingested more chow. The addition of $\beta$-alanine or other amino acids did not change this pattern. In addition, animals fed the LTD were $13 \pm 4 \%$ (SD) smaller, as previously noted $(2,5)$.

On the morning of sacrifice, animals were placed in metabolic cages, with access to water only, for 3-6 h. Urine was collected, and its volume was determined so that creatinine and taurine clearance could be determined as described previously $(5,8)$. Urine and plasma taurine and creatinine were determined as previously described $(2,8)$. From these values, we calculated the fractional excretion of taurine and endogenous creatinine clearance $(2,8)$.

Each animal was killed by placement in anhydrous ether and was then decapitated. The head was allowed to fall into liquid $\mathrm{N}_{2}$ and stored at $-70^{\circ} \mathrm{C}$. The skull was then chipped away, and frozen brain was removed using acid-washed surgical instruments. The brain was divided into cortex, midbrain and pons, and cerebellum. After this separation, a segment of brain was placed in a tared and acid-washed glass homogenizer (Kontes Glass Co., Vineland, NJ). After being weighed, tissue was homogenized in 6\% TCA. Protein-free supernates were separated after centrifugation. All brain samples were acid-hydrolyzed to avoid contamination with phosphadyl ethanolamine and phosphadyl serine, which is found in the brain and elutes near taurine in the amino acid analyzer (11). Taurine is resistant to this acid hydrolysis step.

Membrane vesicle studies. Renal cortex brush border membrane vesicles were isolated by a modification of the method of Booth and Kenny $(5,12)$. The final membrane preparation was suspended in a medium containing $2 \mathrm{mM}$ Tris- $\mathrm{HCl}$ (pH 7.4), $10 \mathrm{mM}$ Hepes, $0.1 \mathrm{mM}$ $\mathrm{MgSO}_{4}$, and $288 \mathrm{mOsm}$ mannitol. The final membrane preparation was in a concentration of 8-10 $\mathrm{mg}$ protein $/ \mathrm{ml}$. Membrane vesicles were used for uptake studies immediately after preparation. Membrane purity was routinely assessed from the enrichment of gamma-glutamyl transferase and 5 -nucleotidase relative to that of the homogenate $(13,14)$. Other enzyme markers of other subcellular fractions, including ouabain-inhibitable $\mathrm{Na}^{+} \mathrm{K}$-ATPase, malate dehydrogenase, succinyl cytochrome-C reductase, acid phosphatase, $N$-acetyl- $\beta$ - $D$-glucosaminidase, and DNA were also routinely assessed by previously described methods (5). The activity of gamma-glutamyl transferase and activity of 5'-nucleotidase were usually more than 11-fold and eightfold greater, respectively, in the final brush border fraction relative to the starting homogenate; the activity of all other enzymes was reduced relative to the starting homogenate.

Protein concentration was assessed by the Lowry technique (15) after precipitation in $6 \%$ trichloroacetic acid.

Uptake of radioactive taurine $\left({ }^{3} \mathrm{H}\right), \beta$-alanine $\left({ }^{3} \mathrm{H}\right)$, other organic solutes, and ${ }^{22} \mathrm{Na}$ was assessed by a filtration technique (Millipore Corp., Bedford, MA) (16). In general, $200 \mu \mathrm{g}$ of membrane suspension was preincubated at $25^{\circ} \mathrm{C}$ for $30 \mathrm{~min}$. Incubation was initiated by adding medium containing known amounts of cold and radiolabeled taurine; usually, $0.5 \mu \mathrm{Ci}$ was added. Incubation media contained either $289 \mathrm{mOsm}$ mannitol, $1 \mathrm{mM} \mathrm{MgSO}_{4}$ and $10 \mathrm{mM}$ Hepes/Tris (pH 7.4), or $100 \mathrm{mM}$ $\mathrm{NaCl}, 89 \mathrm{mOsm}$ mannitol, $1 \mathrm{mM} \mathrm{MgSO}_{4}$, and $10 \mathrm{mM}$ Hepes/Tris. After the desired time interval, a 50- $\mu$ l aliquot was placed on a prewetted $0.45-$ $\mu \mathrm{m}$ filter (HWAP; Millipore Corp.). The filtered sample was washed twice with $3.0 \mathrm{ml}$ of iced wash solution; this process took 8-12 s. The iced "stop solution" contains $289 \mathrm{mOsm}$ mannitol, $1 \mathrm{mM} \mathrm{MgSO}_{4}$, and $10 \mathrm{mM}$ Hepes/Tris ( $\mathrm{pH}$ 7.4). Filters were counted in a scintillation counter as described (5). The nonspecific retention of radiolabel to membranefree samples was $\sim 1$ to $2 \%$ of the specific amount found.

In other studies, the accumulation of other organic solutes-D-glucose $\left({ }^{14} \mathrm{C}\right)$ and L-glycine (Gly) $\left({ }^{3} \mathrm{H}\right)$-was measured in BBMV prepared from adult rats on each of the three sulfur-amino acid diets for $14 \mathrm{~d}$.

The medium used to study the accumulation of ${ }^{22} \mathrm{Na}$ consisted of a preincubation medium of $40 \mathrm{mM} \mathrm{KCl}, 210 \mathrm{mM}$ mannitol, $10 \mathrm{mM}$ Tris Hepes (pH 6.0). The uptake medium consisted of $10 \mathrm{mM}$ Tris Hepes, $\mathrm{pH} 7.5,289 \mathrm{mM}$ mannitol, and $1 \mathrm{mM}^{22} \mathrm{NaCl}$. Membranes were then washed in $150 \mathrm{mM} \mathrm{MgSO}_{4}, 2 \mathrm{mM}$ Tris Hepes (pH 7.5). Uptake was measured at $3,7,15,60$, and $300 \mathrm{~s}$.

All incubations were performed in triplicate, and each experiment was performed on at least four preparations. Uptake values are expressed as picomoles accumulated per mg protein per unit of time. The data at most points represent the mean of at least four determinations, performed in triplicate.

The concentration of taurine was determined on protein-free filtrates of plasma, urine, or cortex and brain homogenates using an amino acid analyzer (model 210; Beckman Instruments, Inc., Fullerton, CA), as described previously $(2,5)$.

Data comparisons were made using Student's $t$ test, linear regression analysis, and analysis of variance (ANOVA) using a desk-top computer with established programs (Texas Instruments Users Guide and Stat Pac, Texas Instruments, Inc., Dallas, TX). Analysis of the kinetics of transport was performed using WISAR (Madison, WI) modification of the method of Neal (17), as described previously (5).

Materials. Materials purchased from New England Nuclear (Boston, MA) included: $\left[2-{ }^{3} \mathrm{H}\right] N$-taurine (specific activity, $20-25 \mathrm{Ci} / \mathrm{mM}$ ), $[1-$ $\left.{ }^{14} \mathrm{C}\right] D$-glucose (specific activity, $329 \mathrm{Ci} / \mathrm{mol}$ ), $\beta-\left[3-{ }^{3} \mathrm{H}\right] N$-alanine (specific activity, $87.0 \mathrm{Ci} / \mathrm{mol}$ ), glycine (specific activity, $44.3 \mathrm{Ci} / \mathrm{mol}$ ), and ${ }^{22} \mathrm{Na}$ (specific activity, $16.376 \mathrm{Ci} / \mathrm{mmol}$ ). Taurine and $\beta$-alanine were stored in $0.1 \mathrm{~N} \mathrm{HCl}$ at $4^{\circ} \mathrm{C}$. Radiochemical purity was confirmed by one-dimensional TLC. All chemicals used to prepare media were reagent grade.

\section{Results}

In vivo studies. As noted in previous studies, both plasma and urine taurine concentrations were related to the type of diet consumed (Table I, and Fig. 1). Plasma taurine level was significantly lower in animals fed the LTD as compared with the NTD. Plasma taurine was higher in rats fed the HTD. Rats fed the $3 \% \beta$-alanine water also showed the same pattern of plasma taurine values depending on the underlying diet consumed (Table I), but the values were lower than in the rats given the basic diets alone. However, this difference between control diet and $3 \% \beta$-alanine-feeding was insignificant.

Urinary taurine excretion is significantly lower in the animals fed the LTD $(P<0.001)$ and higher in those fed the HTD $(P$ $<0.001)$ (Fig. 1). The urinary excretion of taurine $(\mu \mathrm{mol} / \mathrm{mg}$

Table I. Plasma Taurine Levels on Various Diets*

\begin{tabular}{lccl}
\hline & LTD & NTD & HTD \\
\hline & $\mu$ mol/liter & $\mu m o l / l i t e r$ & $\mu m o l / l i t e r$ \\
Control & $137 \pm 26 \ddagger$ & $367 \pm 50$ & $606 \pm 155$ \\
$+3 \% \beta$-ala for $8 \mathrm{~d}$ & $61 \pm 12 \ddagger \S$ & $256 \pm 119$ & $484 \pm 94$ \\
Fasting for last 3 d & $167 \pm 93$ & $192.2 \pm 89$ & $262 \pm 100^{\prime \prime}$ \\
$+3 \% \beta$-ala, plus fasting & & & \\
for last 3 d & $125 \pm 30 \ddagger$ & $266 \pm 80$ & $283 \pm 31^{\prime \prime}$ \\
$+3 \%$ methionine for $8 \mathrm{~d}$ & - & $618 \pm 52 \ddagger$ & - \\
$+3 \%$ glycine for $8 \mathrm{~d}$ & - & $334 \pm 31$ & - \\
& & & \\
\hline
\end{tabular}

* Values represent mean $\pm \mathrm{SE}$ of four to eight determinations. $¥$ Different from NTD, $P<0.05$.

$\S$ Different from value in fasted group on same diet by $P<0.01$. "Different from value in control on same diet by $P<0.01$. 


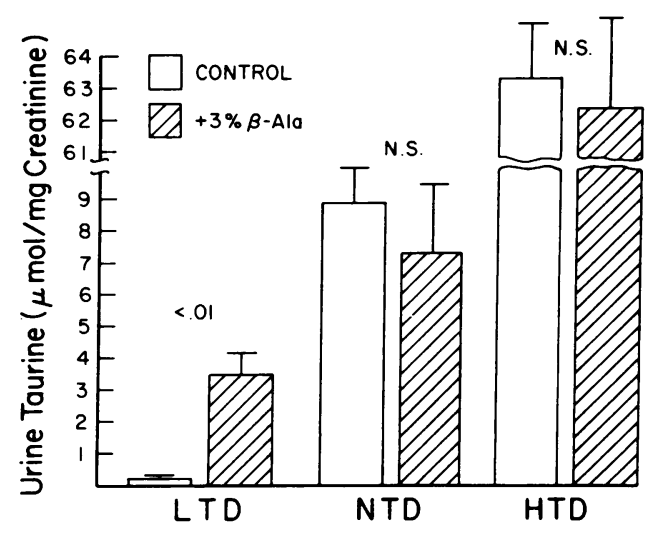

Figure 1. Urinary taurine concentration $(\mu \mathrm{mol} / \mathrm{mg}$ creatinine $(\mathrm{Cr})$ in rats fed the low-taurine diet (LTD), normal taurine diet (NTD), or high-taurine diet (HTD) for $14 \mathrm{~d}(\square)$ or given an additional $3 \% \beta$-alanine $(\beta$-ala) in their drinking water for the final $8 \mathrm{~d}$ of diet $(\square)$ ). Each value is the mean $\pm \mathrm{SE}$ of four to six determinations. The differences between controls and $\beta$-alanine-fed animals are shown.

creatinine) is higher in LTD animals also given $\beta$-alanine ( $P$ $<0.01$ ) but is not different in the animals on the NTD or HTD also fed $\beta$-alanine. Thus, after $8 \mathrm{~d}$ of $\beta$-alanine, the only change in urinary taurine excretion was found in the LTD-fed rats.

The effect of $\beta$-alanine on renal cortex taurine content is shown in Fig. 2. The taurine concentration in cortex is related to dietary intake (Fig. $2 \mathrm{~A}$ ). Rats on the LTD have the lowest concentration of taurine, while those eating the HTD have the highest. In animals on each of the three diets, the ingestion of $\beta$-alanine results in a reduction in cortex taurine content of 45$62 \%(P<0.01$ vs. control). By contrast, the feeding of $3 \%$ glycine or methionine does not alter cortex taurine content (Fig. $2 \mathrm{~B}$ ), whereas $\beta$-alanine feeding in these studies reduces cortex content by $75 \%(P<0.001)$. Hence, the main effect of $\beta$-alanine given for $8 \mathrm{~d}$ is to reduce renal cortex taurine content.

In vitro studies. Most kinetic analyses were performed at 60 $s$, a time period well before the peak of the overshoot for taurine at $360 \mathrm{~s} \mathrm{(5).} \mathrm{Although} \mathrm{our} \mathrm{previous} \mathrm{studies} \mathrm{have} \mathrm{indicated} \mathrm{that}$ uptake is linear between $7 \mathrm{~s}$ and $4 \mathrm{~min}(5)$, the rate of uptake, as shown in Fig. 3, is greater at 10 or $15 \mathrm{~s}$ than at $60 \mathrm{~s}$. However, an examination of the effect of diet on taurine uptake at $15 \mathrm{~s}$ indicates that the $V_{\max }$ is significantly higher in LTD-fed rat vesicles and significantly lower in HTD-fed vesicles both at 15 and $60 \mathrm{~s}$ (Fig. 3). Thus, regardless of the time interval chosen, the adaptive response is maintained.

$\beta$-alanine appears to inhibit the $\mathrm{Na}^{+}$-dependent accumulation of taurine by BBMV. The influence of $\beta$-alanine $(5 \mathrm{mM})$ on taurine uptake $(10 \mu \mathrm{M})$ is shown in Fig. 4. The uptake of taurine is almost completely abolished by co-incubation in $\beta$-alanine.

Nonetheless, after $8 \mathrm{~d}$ of $\beta$-alanine feeding, the uptake of taurine by BBMV is actually higher in each of the three dietary groups (Fig. 5). The most marked difference is seen in the LTD animals where the $\beta$-alanine group has an initial rate $(60 \mathrm{~s})$ of $150 \%$ of control values $(P<0.005)$. In the NTD or HTD groups, significantly higher values are found after $\beta$-alanine feeding $(P$ $<0.05$ ), but they are of a smaller magnitude. At equilibrium (45 $\mathrm{min}$ ), these differences were not apparent.

To explore the possibility that the adaptive response to dietary manipulation in terms of $\mathrm{Na}^{+}$-dependent taurine uptake represents a change in the uptake of sodium, the uptake of ${ }^{22} \mathrm{Na}$ by BBMV prepared from animals on each of the three diets was examined. To maximize ${ }^{22} \mathrm{Na}^{+}$entry, we performed uptake studies in the presence of an outwardly directed $\mathrm{H}^{+}$gradient (pH 6.0 inside, pH 7.5 outside) and outwardly directed $\mathrm{K}^{+}$gradient ( $40 \mathrm{mM} \mathrm{KCl}$ inside). An examination of the time course of uptake indicated that ${ }^{22} \mathrm{Na}$ uptake $(1 \mathrm{mM})$ is linear up to 12 s (data not shown); thus, the uptake of ${ }^{22} \mathrm{Na}$ was measured at 3 and $7 \mathrm{~s}$, as well as later. As indicated in Table II, the uptake of ${ }^{22} \mathrm{Na}$ by vesicles prepared from animals on each diet was similar at time intervals between 3 and $300 \mathrm{~s}$ regardless of diet. Thus, the adaptive response does not seem to be related to charges in the uptake of $\mathrm{Na}$.

Fasting studies. Animals fed each of the three diets for $14 \mathrm{~d}$ underwent a 72-h fast (3 d) before urine collection and sacrifice. Another group was placed on diet for $14 \mathrm{~d}$, received $3 \% \beta$-alanine

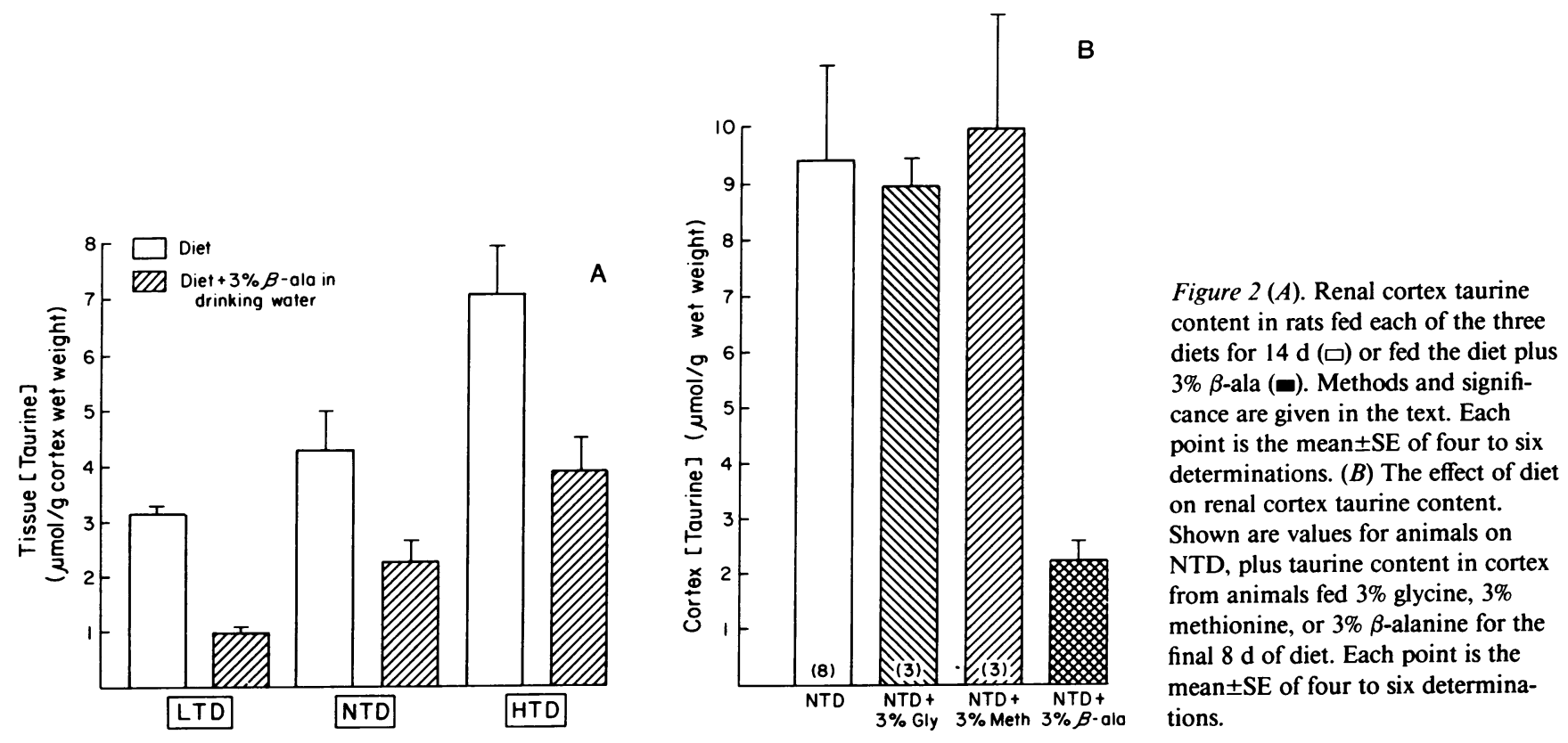




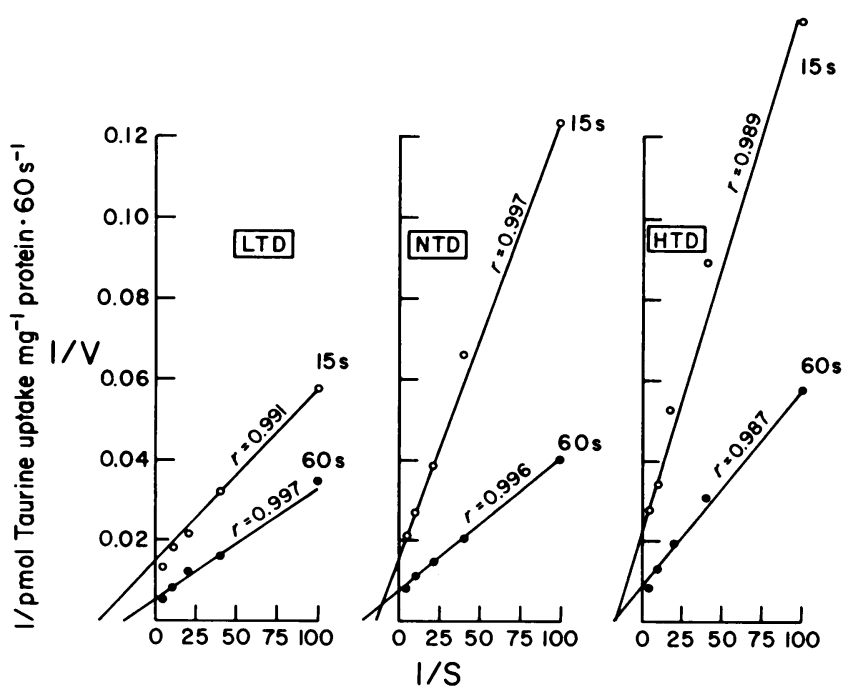

Figure 3. Lineweaver-Burk plot of taurine uptake by BBMV at various concentrations between 10 and $250 \mu \mathrm{M}$. Shown is the uptake at $15 \mathrm{~s}$ (०) and at $60 \mathrm{~s}(\bullet)$ expressed as liter/V (pmol taurine uptake $\mathrm{mg}^{-1}$ protein $\left.\cdot 60 \mathrm{~s}^{-1}\right)$ vs. liter/s $(\mathrm{mM})$. Each point represents the mean of four experiments performed in triplicate.

drinking water over the last $8 \mathrm{~d}$ of diet, and was then fasted for $72 \mathrm{~h}$. During this fast, animals were allowed to drink $3 \% \beta$ alanine water. The effects of these dietary manipulations are shown in Table I for plasma taurine levels, Table III for urinary taurine excretion, Table IV for fractional excretion of taurine, and Table $\mathrm{V}$ for renal cortex taurine pool size.

Fasting values of plasma and urinary taurine concentration do not show the same degree of alteration after dietary manipulation as noted in control studies. These data come from our previous study (4). The combination of $\beta$-alanine in the drinking water and fasting also results in a plasma value and urinary taurine excretion value much like those for NTD animals. The values in plasma are generally lower in the two fasted groups, but no significant differences are found in LTD animals. Urinary taurine is higher in LTD-fed/fasted animals and lower in HTDfed/fasted animals than in the controls on each diet. These differences also are reflected in the fractional excretion patterns. The fractional excretion is higher in LTD-fed/fasted animals and lower in HTD-fed/fasted rats. Despite the patterns of excretion noted previously-hypotaurinuria in LTD and hyper-

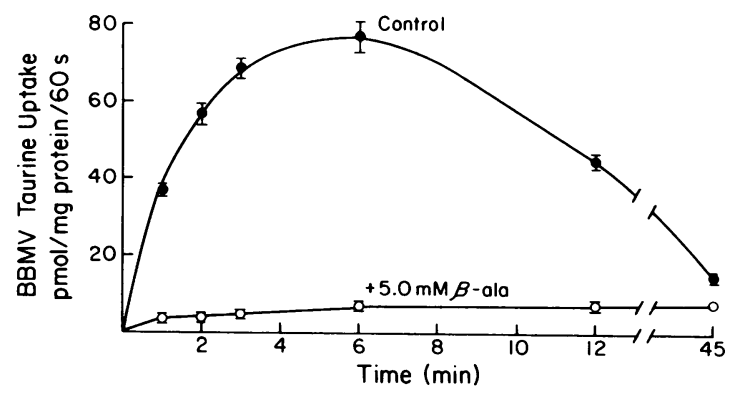

Figure 4. Uptake of taurine by BBMV over time, showing the influence of $5.0 \mathrm{mM} \beta$-alanine in the incubation medium (O) as compared with control (๑). Methods are detailed in the text. Each point represents the mean $\pm \mathrm{SE}$ of four determinations, performed in triplicate.

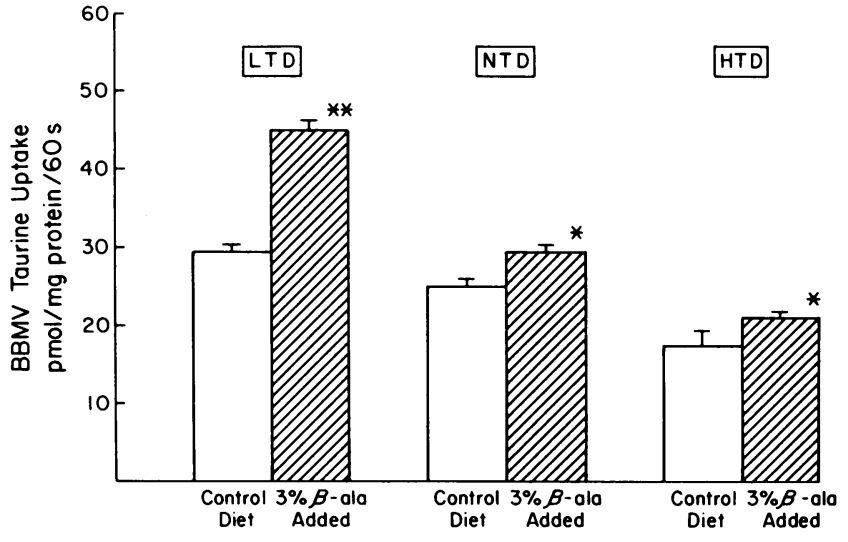

Figure 5. Uptake of taurine $(10 \mu \mathrm{M})$ by BBMV prepared from rats fed the various diets. Each point is the mean $\pm \mathrm{SE}$ of 20 determinations. Level of significance between controls and $\beta$-alanine-fed animals on the various diets is indicated. The difference for taurine uptake by BBMV from animals fed each of the diets is highly significant (LTD vs. NTD, $P<0.001 ;$ HTD vs. LTD, $P<0.001)$ by ANOVA. ${ }^{*} P$ $<0.05 ;{ }^{* *} P<0.005$.

taurinuria in HTD-these differences are far less marked, and all values tend toward those found in NTD animals. The fractional excretion of taurine is slightly, but significantly, higher in rats fed $3 \% \beta$-alanine for $8 \mathrm{~d}$ than in animals fed $\beta$-alanine and then fasted while on LTD or HTD (Table IV). However, no differences in fractional excretion after these two dietary manipulations are found in NTD-fed animals.

Tissue taurine values are lower in fasted and $\beta$-alanine-fed/ fasted animals than in conrols (Table V). For fasted animals, there are 16,25 , and $44 \%$ decrements in tissue taurine for LTD, NTD, and HTD animals, respectively. Fasting plus $\beta$-alanine water results in 41,40 , and $45 \%$ decrements in the same groups, respectively. This decline in tissue taurine content is significantly reduced in the $\beta$-alanine-fed/fasted group on each diet and in the HTD-fasted rats. Thus, although plasma taurine values do not fall significantly vs. comparable control values, the tissue level does fall significantly.

The uptake of $25 \mu \mathrm{M}$ taurine by BBMV prepared from fasted and $\beta$-alanine-fed/fasted animals is shown in Table VI and Fig. 6. The 60-s uptake of BBMV from LTD- and NTD-fasted rats is significantly higher than in controls $(P<0.001)$ but not dif-

Table II. Accumulation of ${ }^{22} \mathrm{NaCl}(1 \mathrm{mM})$ by Brush Border Membrane Vesicles Prepared from Animals on the Various Diets*

\begin{tabular}{rlllll}
\hline Time & LTD & NTD & HTD & $\begin{array}{l}\text { LTD } \\
\text { NTD }\end{array}$ & $\begin{array}{l}\text { HTD vs. } \\
\text { NTD }\end{array}$ \\
\hline$s$ & $\begin{array}{l}\text { pmol/mg } \\
\text { protein }\end{array}$ & $\begin{array}{l}\text { pmol/mg } \\
\text { protein }\end{array}$ & $\begin{array}{l}\text { pmol/mg } \\
\text { protein }\end{array}$ & $\begin{array}{l}\text { pmol/mg } \\
\text { protein }\end{array}$ & $\begin{array}{l}\text { pmol/mg } \\
\text { protein }\end{array}$ \\
3 & $128.3 \pm 9.8$ & $151.2 \pm 12.4$ & $153.3 \pm 6.3$ & NS & NS \\
7 & $238.1 \pm 7.7$ & $227.0 \pm 16.5$ & $265.1 \pm 10.8$ & NS & NS \\
15 & $333.5 \pm 10.9$ & $319 \pm 9.7$ & $361.8 \pm 19.1$ & NS & NS \\
60 & $602.6 \pm 22.8$ & $657.2 \pm 32.1$ & $599.1 \pm 20.9$ & NS & NS \\
300 & $1066.4 \pm 33.2$ & $1081.4 \pm 52.9$ & $1065.5 \pm 19.3$ & NS & NS
\end{tabular}

* Each point is the mean $\pm S E$ of four determinations, performed in triplicate.

$¥$ Differences by ANOVA. 
Table III. Urinary Taurine Excretion*

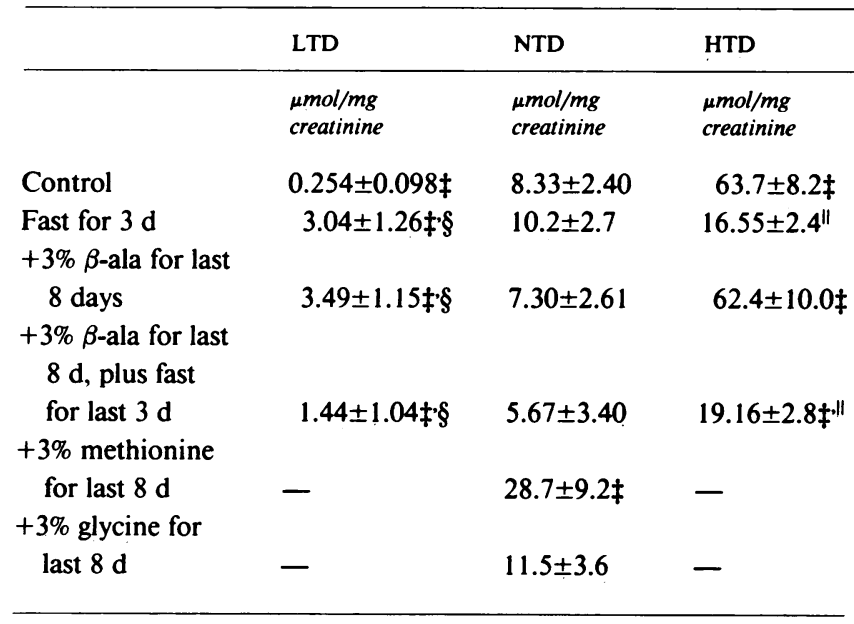

* Values represent mean $\pm \mathrm{SE}$ of four to eight determinations. $\ddagger$ Different from NTD by $P<0.05$ or less.

$\S$ Different from control for same basic diet by $P<0.5$ or less.

"Different from control of $+3 \% \beta$-ala for same basic diet by $P<0.05$ or less.

ferent from each other. The addition of fasting to $\beta$-alanine feeding also affects BBMV uptake in that vesicles from all groups are significantly higher than control $(P<0.001)$ but not different from each other. Thus, all of the maneuvers that reduce renal cortex tissue taurine pool size result in enhanced uptake of taurine.

Kinetic analysis of BBMV uptake in fasted rats over the concentration range $10-250 \mu \mathrm{M}$ taurine revealed similar $K_{\mathrm{m}}$ values of $40-46 \mu \mathrm{M}$ in all three groups and a $V_{\max }$ of 252 and $258 \mathrm{pmol} / \mathrm{mg}$ protein per $60 \mathrm{~s}$ for LTD- and NTD-fasted animals, and $128 \mathrm{pmol} / \mathrm{mg}$ protein per $60 \mathrm{~s}$ for HTD-fed rats. The kinetics of BBMV uptake over the same concentration range was similar among LTD, NTD, and HTD groups in the $\beta$-alanine-fed/fasted animals (data not shown). The $K_{\mathrm{m}}$ of uptake was 47-54 $\mu \mathrm{M}$, and the $V_{\max }$ ranged from 225 to $240 \mathrm{pmol} / \mathrm{mg}$ protein per 60

Table IV. Fractional Excretion of Taurine by Rats on Each Diet *

\begin{tabular}{|c|c|c|c|}
\hline & LTD & NTD & HTD \\
\hline Control & $\begin{array}{l}0.0114 \pm 0.0026 \ddagger \\
(n=11)\end{array}$ & $\begin{array}{l}0.0742 \pm 0.0228 \\
(n=11)\end{array}$ & $\begin{array}{l}0.583 \pm 0.036 \ddagger \\
(n=11)\end{array}$ \\
\hline Fast for $3 \mathrm{~d}$ & $\begin{array}{l}0.093 \pm 0.009 \S \\
(n=5)\end{array}$ & $\begin{array}{l}0.168 \pm 0.023 \S \\
(n=5)\end{array}$ & $\begin{array}{l}0.138 \pm 0.012 \S \\
(n=5)\end{array}$ \\
\hline $\begin{array}{l}+3 \% \beta \text {-ala for } \\
\text { last } 8 \mathrm{~d}\end{array}$ & $\begin{array}{l}0.1792 \pm 0.0524 \S \\
(n=4)\end{array}$ & $\begin{array}{l}0.0593 \pm 0.0648 \\
(n=4)\end{array}$ & $\begin{array}{l}0.245 \pm 0.006 \ddagger \S \\
(n=4)\end{array}$ \\
\hline $\begin{array}{l}+3 \% \beta \text {-ala for } \\
\text { last } 8 \mathrm{~d} \text {, plus } \\
\text { fast for last } \\
3 \mathrm{~d}\end{array}$ & $\begin{array}{l}0.0337 \pm 0.0241 \\
(n=3)\end{array}$ & $\begin{array}{l}0.0568 \pm 0.0264 \\
(n=3)\end{array}$ & $\begin{array}{l}0.1392 \pm 0.0022 \ddagger \S \\
(n=3)\end{array}$ \\
\hline $\begin{array}{l}+3 \% \text { methionine } \\
\text { for last } 8 d\end{array}$ & - & $0.1104 \pm 0.0341$ & - \\
\hline
\end{tabular}

* Units of measure, urine/plasma taurine divided by urine/plasma creatinine. Values represent mean $\pm \mathrm{SE}$.

$\ddagger$ Different from NTD by $P<0.001$.

$\S$ Different from control for a given diet by $P<0.05$ or less. s. Compared with NTD and HTD control animals, the $K_{\mathrm{m}}$ is similar in each group, and the $V_{\max }$ values are significantly higher for all $\beta$-alanine-fed/fasted groups and for LTD- and NTD-fasted groups, but not for the HTD-fasted group. No significant differences were found between control LTD kinetic values and those for all fasted groups $\left(K_{\mathrm{m}}=56 \mu \mathrm{M} ; V_{\max }=191.9 \mathrm{pmol}\right.$ taurine uptake/mg vesicle protein per $60 \mathrm{~s}$ ), except that fasted values are higher. Hence, fasting maneuvers that lower tissue taurine levels result in kinetic parameters of amino acid uptake similar to those in our previous report (5), with $V_{\max }$ values greater than the control situation whenever vesicles from LTDfed animals were employed.

We attempted to define a relationship between the change in renal cortex taurine concentration (as compared with NTDcontrol) and the change in BBMV uptake under each experimental situation (as compared with NTD-control), or, in effect, the change in tissue taurine as compared with the change in BBMV initial taurine uptake. An inverse relationship was defined: $y=-1.005 x+2.14, r=0.547, P<0.01$. We also examined the relationship between the change in plasma taurine as compared with NTD-control values and the change in BBMV taurine uptake. Another inverse relationship was defined: $y$ $=-0.7534 x+1.87, r=0.788, P<0.001$. Finally, we explored the relationship between the change in fractional excretion of taurine and the change in BBMV uptake. An inverse relationship again was found: $y=-0.097 x+1.52, r=-0.458$, not significant.

According to these findings, the increased accumulation of taurine by BBMV is correlated to the decline in tissue taurine content and to the change in the plasma taurine level but not to the fractional excretion of taurine.

Other amino acids. The effect of methionine and glycine feeding is shown in Tables I, III, and IV, and Fig. 7. Plasma taurine levels are significantly higher in rats on the NTD that are fed the $3 \%$ methionine diet $(618 \pm 52$ vs. $367 \pm 50 \mu \mathrm{mol} / \mathrm{liter}$, $P<0.01$ ); the urinary excretion of taurine is also higher in these rats $(28.7 \pm 9.2$ vs. $8.3 \pm 2.40 \mu \mathrm{mol} / \mathrm{mg}$ creatinine, $P<0.05)$. No change is found in the fractional excretion of taurine (Table IV) or in the renal cortex concentration of taurine after methionine feeding (Fig. 2). Glycine feeding does not alter the concentration of taurine in plasma, urine, or renal cortex or the fractional excretion of taurine.

Neither methionine nor glycine changes the time course of taurine uptake by BBMV prepared from animals fed the NTD (Fig. 7).

The uptake of glycine by BBMV prepared from animals on each of the three diets also was examined (Fig. 8). Glycine uptake over time is similar in BBMV from animals fed the LTD and NTD, and is slightly, but significantly, reduced in BBMV from HTD-fed animals. These differences are significant at $60 \mathrm{~s}$ and later $(P<0.01)$. $D$-glucose uptake by BBMV from animals on each of the three diets was not altered (data not shown). Again, $D$-glucose uptake by BBMV is lowest in the HTD-fed group, but this difference is not significant.

Adaptation at high taurine levels. The effects of high concentrations of taurine on taurine accumulation are shown in Fig. 9. Also indicated is the influence of dietary change on taurine uptake. From this Eadie-Hofstee plot, it is evident that the low $K_{\mathrm{m}}$, high affinity site is influenced by diet and that high $K_{\mathrm{m}}$ uptake is unaltered by diet. It is also apparent that the uptake of taurine at high concentrations in the absence of $\mathrm{Na}$ is different than at low taurine concentrations. When taurine accumulation is examined at $15 \mathrm{~s}$, the $\mathrm{Na}^{+}$-independent uptake of taurine is 
Table V. Taurine Concentration in Renal Cortex Homogenates from Rats Fed Various Diets*

\begin{tabular}{llllll}
\hline & LTD & NTD & HTD & LTD vs. NTD & HTD vs. NTD \\
\hline Control & $3.15 \pm 0.16$ & $4.30 \pm 0.68$ & $7.10 \pm 0.84$ & NS & $<0.05$ \\
$\begin{array}{l}\text { Fast for } 3 \mathrm{~d} \\
+3 \% \beta \text {-ala for last } 8 \mathrm{~d}\end{array}$ & $2.66 \pm 0.65$ & $3.22 \pm 0.31$ & $3.95 \pm 0.49 \ddagger$ & NS & NS \\
$+3 \% \beta$-ala for last $8 \mathrm{~d}$, & $0.96 \pm 0.11 \ddagger$ & $2.27 \pm 0.38 \ddagger$ & $3.91 \pm 0.74 \ddagger$ & $<0.05$ & NS \\
$\quad$ plus fast for last $3 \mathrm{~d}$ & $1.85 \pm 0.17 \ddagger$ & $2.56 \pm 0.16 \ddagger$ & $3.87 \pm 0.21 \ddagger$ & $<0.05$ & $<0.05$ \\
\hline
\end{tabular}

* Values represent mean $\pm \mathrm{SE}$ of three to six determinations. $¥$ Different from control on same diet at $P<0.05$ or less.

$7.5 \%$ of $\mathrm{Na}^{+}$-dependent uptake at $10 \mu \mathrm{M}$, while at $5.0 \mathrm{mM}, \mathrm{Na}^{+}$. independent uptake is $67.9 \%$ of $\mathrm{Na}^{+}$-dependent uptake, $P$ $<0.0001$. An Eadie-Hofstee plot of 15-s uptake data shows that the upright limb (seen in Fig. 9) over the range 0.75 to $10.0 \mathrm{mM}$ taurine and performed in the absence of $\mathrm{Na}^{+}$is parallel to the line in the presence of $\mathrm{Na}^{+}$, which indicates that uptake in the absence of $\mathrm{Na}^{+}$probably represents diffusion (not shown). These data strongly suggest that adaptation to dietary alteration is not evident for $\mathrm{Na}^{+}$-independent taurine uptake.

Brain taurine content. Although taurine concentration in renal cortex changed in relation to the dietary intake of sulfur amino acids and fasting, the concentration of taurine in brain did not change (Table VII). Neither the HTD nor the LTD altered the taurine concentration of brain cortex, midbrain and pons, or cerebellum. Fasting for $72 \mathrm{~h}$ also did not change the brain content of taurine. Hence, maneuvers that alter renal tissue and plasma taurine content as well as BBMV uptake do not alter the content of taurine in three separate brain segments.

\section{Discussion}

Using a variety of manipulations, we were able to reduce cortex taurine content in animals fed low, normal, or high sulfur-amino acid diets. These manipulations resulted in greater accumulation of taurine by brush border membrane vesicles isolated from animals on each of the altered diets. First, $\beta$-alanine, given in the drinking water of the rats for the final $8 \mathrm{~d}$ of diet, blocks the uptake of taurine by renal cortex, since it is a competitive inhibitor at the renal $\beta$-amino acid transport site. $\beta$-alanine will lower renal cortex taurine levels $(6)$ as well as reduce the active accumulation of taurine by BBMV. However, in these animals fed the $\beta$-alanine in their drinking water, which lowers cortex taurine levels, the uptake of taurine by BBMV is actually greater. This paradox - greater accumulation of taurine by vesicles after chronic $\beta$-alanine feeding than in controls on each of the dietsrequires explanation. $\beta$-alanine may deplete tissue taurine content by acutely decreasing taurine uptake or by augmenting taurine efflux (an effect not examined in this study). With the 45$75 \%$ change in renal cortex taurine pool size, the uptake of taurine is actually increased in the in vitro BBMV studies.

Fasting or fasting with continued $\beta$-alanine in the drinking water also lowers cortex taurine content and enhances initial taurine uptake by BBMV. These manipulations result in higher accumulation by vesicles in all three groups either fasted alone or in $\beta$-alanine-fed and fasted animals. Thus, the change in tissue taurine content continues to correlate with the change in BBMV uptake, but not with changes in the fractional excretion of taurine, being higher than control in initially LTD-fed and lower in initially HTD-fed animals.

Rozen et al. (3) and our previous study (5) indicated that the plasma taurine level inversely correlated with the change in BBMV uptake in animals fed the low and high sulfur-amino

Table VI. Uptake of $25 \mu$ M Taurine by Brush Border Membrane Vesicles Prepared from Animals on the Various Diets*

\begin{tabular}{|c|c|c|c|c|c|}
\hline Condition & LTD & NTD & HTD & $\begin{array}{l}\text { LTD } \ddagger \text { vs. } \\
\text { NTD }\end{array}$ & $\begin{array}{l}\text { HTD vs. } \\
\text { NTD }\end{array}$ \\
\hline & $\begin{array}{l}\mathrm{pmol} / \mathrm{mg} \\
\text { protein } / 60 \mathrm{~s}\end{array}$ & $\begin{array}{l}\text { pmol/mg } \\
\text { protein } / 60 \mathrm{~s}\end{array}$ & $\begin{array}{l}\mathrm{pmol} / \mathrm{mg} \\
\text { protein } / 60 \mathrm{~s}\end{array}$ & $\begin{array}{l}\mathrm{pmol} / \mathrm{mg} \\
\text { protein } / 60 \mathrm{~s}\end{array}$ & $\begin{array}{l}\mathrm{pmol} / \mathrm{mg} \\
\text { protein } / 60 \mathrm{~s}\end{array}$ \\
\hline Control & $60.21 \pm 1.97$ & $48.60 \pm 1.3$ & $33.16 \pm 3.7 t$ & $<0.001$ & $<0.001$ \\
\hline$+3 \% \beta$-ala for last $8 d$ & $96.28 \pm 7.21$ & $64.84 \pm 1.6$ & $46.32 \pm 1.8$ & $<0.001$ & $<0.001$ \\
\hline Fast for $3 \mathrm{~d}$ & $84.92 \pm 3.0$ & $80.55 \pm 2.1$ & $38.03 \pm 1.9$ & NS & NS \\
\hline $\begin{array}{l}+3 \% \beta \text {-ala for last } 8 \\
\quad \mathrm{~d} \text {, plus fast for last } \\
\quad 3 \mathrm{~d}\end{array}$ & $74.99 \pm 3.16$ & $75.16 \pm 3.23$ & $74.01 \pm 2.46$ & NS & NS \\
\hline
\end{tabular}

\footnotetext{
* Each point is the mean $\pm \mathrm{SE}$ of 4-7 determinations, performed in triplicate. $\ddagger$ Differences by ANOVA.
} 


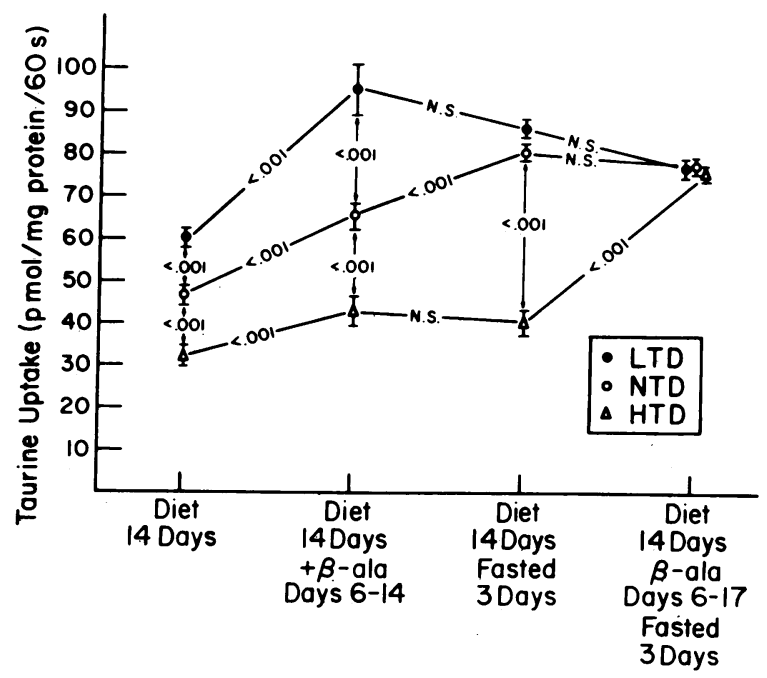

Figure 6. Taurine uptake by BBMV over $60 \mathrm{~s}$ using $25 \mu \mathrm{M}$ taurine on the various diets. Each point represents the mean $\pm S E$ of four to six determinations, performed in triplicate.

acid diets. The manipulations carried out in this study ( $\beta$-alanine feeding, fasting, and fasting with continued $\beta$-alanine feeding) do not significantly change plasma taurine values in the LTD and NTD animals, and they reduce plasma taurine levels only in the fasted HTD groups. Nonetheless, the change in BBMV uptake is significantly higher in all these groups as compared with control groups on each diet. Thus, despite no significant change in plasma taurine content, accumulation of taurine increases at the brush border surface. A significant inverse correlation was found between the change in plasma taurine and the change in BBMV uptake. However, this condition relates to the general overall difference in plasma taurine concentrations between the three dietary groups: plasma taurine is low in LTD groups and high in HTD groups under all conditions. Since no significant differences are found in plasma levels between the various subsets on a given diet, it is far less likely that plasma taurine is regulating the adaptive response or changes found in BBMV uptake.

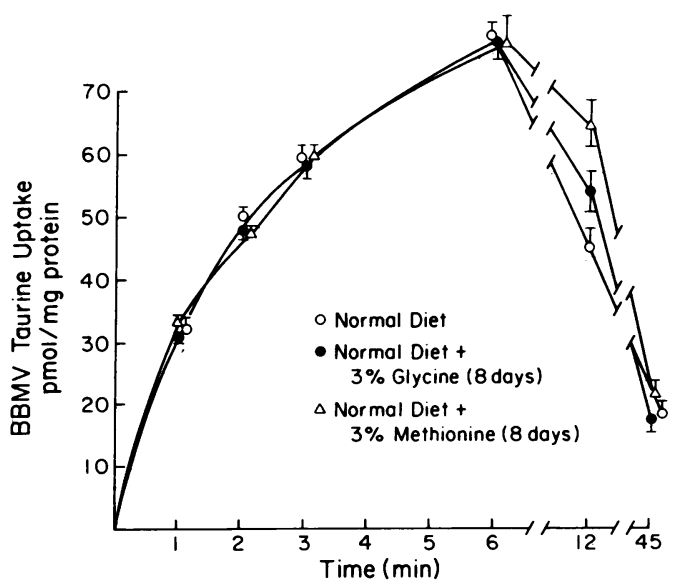

Figure 7. Taurine $(10 \mu \mathrm{M})$ uptake over time by BBMV from animals fed the various diets. No difference in uptake is noted whether $3 \%$ glycine, $3 \%$ methionine, or control diet is given. Each point represents the mean $\pm \mathrm{SE}$ of four determinations, performed in triplicate.

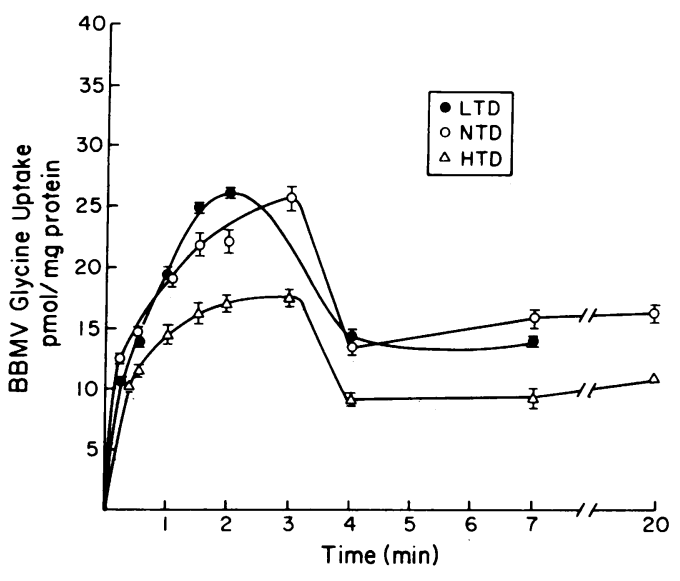

Figure 8. Glycine uptake by BBMV prepared from animals fed each of the diets as shown. Each point represents the mean \pm SE of four determinations. No difference in uptake between animals fed the LTD and HTD is noted. A slight, but significant reduction in glycine uptake was found in animals fed the HTD, $P<0.001$.

Feeding of $3 \%$ glycine or methionine does not alter either renal cortex taurine pool size or change the accumulation of taurine. Methionine feeding increases plasma taurine levels, probably because methionine is a precursor of taurine synthesis $(10,18)$. This increased plasma level is reflected by an augmented urinary excretory pattern, although the fractional excretion of taurine, while higher, is not significantly higher. Moreover, the increase in plasma taurine associated with feeding a precursor of taurine is not associated with any alteration in BBMV uptake. At a plasma taurine level comparable to that found in rats fed the HTD, BBMV uptake by rats fed 3\% methionine does not show the reduction in uptake found in BBMV from HTD rats. Under this circumstance, the plasma taurine level does not appear to govern BBMV transport, and the adaptive response does not occur.

Glycine feeding does not alter the renal reabsorption of

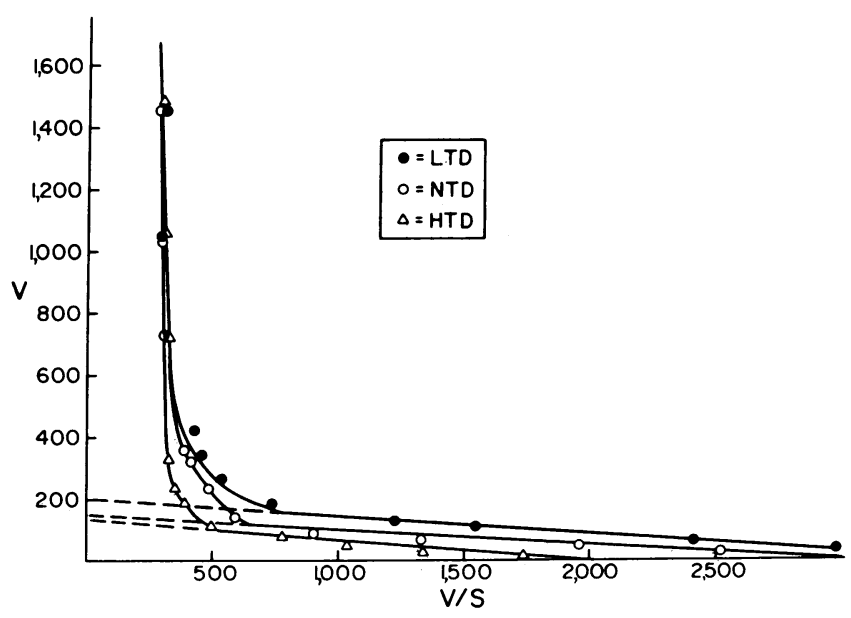

Figure 9. Eadie-Hoffstee plot of taurine uptake $(60 \mathrm{~s})$ over the range 0.010 to $5.0 \mathrm{mM}$ indicating the influence of diet on uptake. On the low $K_{\mathrm{m}}$, high affinity limb, significant differences $(P<0.01)$ are noted in the $X$ and $Y$ intercepts dependent on diet. No change is noted on the high $K_{\mathrm{m}}$, low affinity limb. Each point is the mean of six determinations, performed in triplicate. 
Table VII. Concentration of Taurine in Acid-hydrolyzed Brain*

\begin{tabular}{llll}
\hline & LTD & NTD & HTD \\
\hline Cortex & & & \\
$\quad$ Fed & $3.52 \pm 0.73 \ddagger \S$ & $2.76 \pm 0.27$ & $3.55 \pm 0.52 \ddagger$ \\
Fasted & $2.45 \pm 0.21 \ddagger \S$ & $3.08 \pm 0.21$ & $2.91 \pm 0.38 \ddagger$ \\
Cerebellum & & & \\
$\quad$ Fed & $2.31 \pm 0.23 \ddagger \S$ & $2.53 \pm 0.16$ & $3.65 \pm 0.75 \ddagger$ \\
$\quad$ Fasted & $1.86 \pm 0.24 \ddagger \S$ & $2.16 \pm 0.14$ & $2.61 \pm 0.51 \ddagger$ \\
Midbrain and pons & & & \\
$\quad$ Fed & $3.96 \pm 0.42 \ddagger \S$ & $5.00 \pm 0.94$ & $5.79 \pm 0.59 \ddagger$ \\
$\quad$ Fasted & $3.89 \pm-0.53 \ddagger \S$ & $4.96 \pm 0.23$ & $4.60 \pm 0.94 \ddagger$ \\
& & &
\end{tabular}

* Units of measure, $\mu \mathrm{mol} / \mathrm{g}$ tissue wet weight. Values represent mean \pm SE.

$\ddagger$ Value vs. NTD, not significant.

$\S$ LTD vs. HTD, not significant.

BBMV uptake of taurine. Similarly, glycine uptake by BBMV is not altered by changing the dietary intake of sulfur amino acids. Accordingly, the effect of dietary change in amino acid intake on taurine reabsorption and uptake is dependent on changes in the intake of the $\beta$-amino acids taurine and $\beta$-alanine, or a precursor $\alpha$-amino acid, methionine, rather than on changes in $\alpha$-amino acid intake. Likewise, changes in $\beta$-amino acid uptake do not alter $\alpha$-amino acid accumulation as would be predicted from the studies of other laboratories concerning the group specificity of renal amino acid transport (19-23). The effect of changes in dietary $\alpha$-amino acid intake was recently examined by Grosvenor and Zeman (24), who studied the transport of $\alpha$ aminoisobutyrate ( $\alpha$-AIB) and glycine in tubules from fetal rats whose mothers were fed a protein-restricted diet (4\% vs. $24 \%$ protein). The uptake of $\alpha$-AIB over its time course of uptake was significantly higher in protein-restricted rat pup kidneys, as was the uptake of glycine at $15 \mathrm{~min}$ (initial rate uptake). However, since a $4 \%$ casein diet would also severely limit methionine and taurine intake $(18,25)$, it is unfortunate that taurine accumulation was not also examined.

Despite the changes in plasma, renal cortex, and urinary taurine concentrations brought about by changes in the intake of sulfur amino acids, fasting and $\beta$-alanine feeding, the brain taurine concentration is unchanged. During periods of undernutrition, renal conservation of taurine is evident, expressed at the brush border surface, and brain taurine content remains constant. With dietary sufficiency, excess taurine is excreted and brush border uptake is reduced, yet brain taurine is unaltered.

Thus, this study provides evidence that the renal adaptive response to alterations in the intake of sulfur amino acids may serve the role of maintaining the availability of taurine, a known neurotransmitter, in proximity to excitable membranes $(26,27)$.

This study also provides evidence that the renal adaptive response to altered dietary intake of sulfur amino acids, which is expressed at the renal brush border surface, relates in part to changes in the content of taurine in the renal cortex. These changes in uptake occur despite varying changes in the fractional excretion of taurine and without any significant alteration in plasma taurine levels. Indeed, the feeding of 3\% methionine in conjunction with the NTD results in a higher plasma taurine level but no change in renal cortex taurine content or BBMV uptake, thus providing further evidence of the role of renal tissue taurine content on the adaptive response. The constancy of brain taurine values suggests that the kidney is the site of the regulation of body stores of this neurotransmitter. However, the manner in which the changes in tubule cell taurine content are expressed as changes in the membrane transport sites for taurine is unknown and awaits further investigation.

\section{Acknowledgments}

This study was supported in part by grants from U. S. Public Health Service (R01 AM31682-01) and from the Medical School and Graduate School Research Committees of the University of Wisconsin. Dr. Dabbagh is supported by the Pearl M. Stetler Foundation, Dr. Chesney is the recipient of a Research Career Development Award from U. S. Public Health Service (K04 AM00421).

\section{References}

1. Friedman, A. L., P. W. Albright, and R. W. Chesney. 1981. Dietary adaptation of taurine transport by rat renal epithelium. Life Sciences. 29:2415-2419.

2. Friedman, A. L., P. W. Albright, N. Gusowski, M. Padilla, and R. W. Chesney. 1983. Renal adaptation to alteration in dietary amino acid intake. Am. J. Physiol. 245:F159-F166.

3. Rozen, R., and C. R. Scriver. 1982. Renal transport of taurine adapts to perturbed taurine homeostasis. Proc. Natl. Acad. Sci. USA. 79: 2101-2105.

4. Chesney, R. W., A. L. Friedman, P. W. Albright, and N. Gusowski. 1982. Fasting reverses the renal adaptation to altered dietary amino acid intake. Proc. Soc. Exp. Biol. Med. 170:493-501.

5. Chesney, R. W., N. Gusowski, and A. L. Friedman. 1983. Renal adaptation to altered dietary sulfur amino acid intake occurs at luminal brush border membrane. Kidney Int. 24:588-594.

6. Shaffer, J. E., and J. J. Kocsis. 1981. Taurine mobilizing effects of $\beta$-alanine and other inhibitors of taurine transport. Life Sciences. 28: $2727-2736$.

7. Kempson, S. A., S. V. Shah, P. G. Werness, T. Berndt, P. H. Lee, L. H. Smith, F. G. Knox, and T. P. Dousa. 1980. Renal brush border membrane adaptation to phosphorus deprivation: effects of fasting versus low-phosphorus diet. Kidney Int. 18:36-47.

8. Chesney, R. W., and D. K. Jax. 1979. Developmental aspects of renal $\beta$-amino acid transport: I. Ontogeny of taurine reabsorption and accumulation in renal cat cortex. Pediatr. Res. 13:854-860.

9. Chesney, R. W., and D. K. Jax. 1979. Developmental aspects of renal $\beta$-amino acid transport: Il. Ontogeny of uptake and efflux processes and effect of anoxia. Pediatr. Res. 13:861-867.

10. Huxtable, R. J., and S. E. Lippincott. 1982. Diet and biosynthesis as sources of taurine in the mouse. J. Nutr. 87:267-273.

11. Tachiki, K. H., R. A. Baldwin, and C. F. Baxter. 1978. Pitfalls in the use of the automated amino acid analyzer for the quantitation of some acidic amino acids in brain tissues. Soc. Neurosci. Abstr. 4:452.

12. Booth, A. G., and A. J. Kenny. 1974. A rapid method for the preparation of microvilli from rabbit kidney. Biochem. J. 142:575-581.

13. Glossman, H., and D. M. Neville, Jr. 1972. $\gamma$-glutamyl transferase in kidney brush border membranes. FEBS Lett. 19:340-344.

14. Dixon, T. F., and M. Purdom. 1954. Serum 5-nucleotidase. $J$. Clin. Pathol. 7:341-343.

15. Lowry, O. H., N. J. Rosebrough, A. L. Farr, and R. J. Randall. 1951. Protein measurement with the folin phenol reagent. J. Biol. Chem. 193:265-275.

16. Chesney, R. W., B. Sacktor, and R. R. Rowen. 1973. The binding of D-glucose to the isolated rabbit renal brush border. J. Biol. Chem. 218:2182-2191.

17. Neal, J. L. 1972. Analysis of Michaelis kinetics for two independent saturable membrane transport functions. J. Theor. Biol. 35:113118. 
18. Rogers, Q. R., and A. E. Harper. 1965. Amino acid diets and maximal growth. J. Nutr. 87:267-273.

19. Mitch, W. E., and R. W. Chesney. 1983. Amino acid metabolism by the kidney. Mineral Electrolyte Metab. 9:190-202.

20. Scriver, C. R., R. W. Chesney, and R. R. McInnes. 1976. Genetic aspects of renal tubular transport: diversity and topology of carriers. Kidney Int. 9:149-171.

21. Silbernagl, S., E. C. Foulkes, and P. Deetjen. 1975. Renal transport of amino acids. In Reviews of Physiology, Biochemistry and Pharmacology. Vol. 74. Springer-Verlag, Berlin. 105-167.

22. Segal, S., and S. O. Their. 1973. Renal handling of amino acids. In Handbook of Physiology. Vol. 8 (Renal Physiology). American Physiological Society, Williams \& Wilkins, Washington. 653-676.
23. Young, J. A., and B. S. Freedman. 1971. Renal tubular transport of amino acids. Clin. Chem. 17:245-266.

24. Grosvenor, M. B., and F. J. Zeman. 1983. In vitro amino acid transport by renal tubules of prenatally protein-deprived fetal rats. $J$. Nutr. 113:1513-1520.

25. Coates, M. E., D. N. O'Donoghue, P. R. Doyne, and R. J. Ward, editors. 1969. Dietary standards for laboratory rats and mice. In Laboratory Animal Handbook No. 2. London Laboratory, Ltd., London.

26. Wen, G. Y., J. A. Sturman, H. M. Wisniewski, A. A. Lidsky, A. C. Cornwell, and K. C. Hayes. 1979. Tapetum disorganization in taurine-depleted cats. Invest. Ophthalmol. Vis. Sci. 18:1201-1206.

27. Huxtable, R. J. 1981. Insights on functions: metabolism and pharmacology of taurine in the brain. In The Role of Peptides and Amino Acids as Neurotransmitters. Alan R. Liss, Inc., New York. 53-97. 